\title{
Die invloed van landboupraktyke op grondlewende mesofauna van geselekteerde agro-ekosisteme in die Vrystaat, Suid-Afrika
}

\section{Outeurs: \\ Hannelene Badenhorst ${ }^{a}$ CR Haddad ${ }^{\mathrm{a}}$ \\ C Janion-Scheepers ${ }^{b}$ SvdM Louw ${ }^{\mathrm{a}^{+}}$(oorlede) \\ Affiliasie: \\ a Departement Dierkunde en Entomologie, Universiteit van die Vrystaat, Posbus 339, Bloemfontein, 9300, Suid-Afrika ${ }^{b}$ Department Biologiese Wetenskappe, Universiteit van Kaapstad, Privaatsak X3, Rondebosch, 7701, Suid-Afrika}

Korresponderende outeur: Hannelene Badenhorst E-pos:

badenhorsth@ufs.ac.za

† Ter herinnering aan Prof SvdM Louw

Hoe om hierdie artikel aan te haal:

Hannelene Badenhorst, CR Haddad, C JanionScheepers, SvdM Louw, Die invloed van landboupraktyke op gronlewende mesofauna van geselekteerde agro-ekosisteme in die Vrystaat, Suid-Afrika, Suid-Afrikaanse Tydskrif vir Natuurwetenskap en Tegnologie 39(1) (2020). https://doi.org/10.36303/ SATNT.2020.39.1.809

\section{Kopiereg:}

(C) 2020. Authors.

Licensee: Die SuidAfrikaanse Akademie vir Wetenskap en Kuns. Hierdie werk is onder die Creative Commons Attribution License gelisensieer.

\begin{abstract}
Influences of agricultural practices on soil mesofauna of selected agroecosystems in the Free State, South Africa: Soil is a complex medium, comprised of biotic and abiotic components. Interactions between these components are responsible for beneficial services provided within ecosystems, including agroecosystems. The evaluation of soil samples from six farms in the Free State indicate that soils with less disturbance have complex biological communities and are more resilient.
\end{abstract}

Grond is 'n komplekse medium wat uit beide biotiese en abiotiese komponente saamgestel is. Die biotiese komponent, wat ook na verwys word as die aktiewe rolspelers in die grond, is vir die lewering van voordelige ekosisteemdienste verantwoordelik, maar sluit ook skadelike organismes in. Die voorkoms van hierdie organismes word hoofsaaklik deur abiotiese faktore beïnvloed wat as filtreringsmeganismes dien, en dus vir die voorkoms van geselekteerde spesies in spesifieke gebiede verantwoordelik is. Met verwysing na die groeiende menslike bevolking, kan hierdie dienste as voordeel aangewend word deurdat dit oesopbrengste met minimale insetkostes kan verhoog sonder om die grond uit te buit. Baie boere is in die proses om hul boerderymetodes aan te pas na 'n meer volhoubare stelsel, met bewaring en herlewing as uitgangspunte. Dit is slegs moontlik indien versteuring in grondstrukture geminimaliseer word en voedselbrondiversiteit toeneem, wat 'n hoër grondgemeenskapkompleksiteit tot gevolg het en dus veerkragtigheid van grondgemeenskappe verseker. Chemiese en meganiese versteurings verlaag die kompleksiteit van grondgemeenskappe, wat daartoe lei dat voordelige ekosisteemdienste ingekort word. Hierdie studie fokus op die fluktuasies in diversiteit van geselekteerde rolspelers binne die grondmedium aan die hand van die teenwoordigheid van sekere landboupraktyke en omgewingsveranderlikes.

Grondmonsters is tussen 2011 en 2014 by ses terreine in die Vrystaat versamel. Die plase Vaaldam, Koppieskraal, Thornberry en Klein Brittanje is weens die diverse landboupraktyke en bestuurstrategieë wat hulle daar toepas, geselekteer. Die ander terreine was die Paradysproefplaas van die Universiteit van die Vrystaat, waar 'n proef met plaagdoders uitgevoer is, en die plaas Eureka, wat aan besoedeling van 'n nabygeleë goudmynslikdam blootgestel was. $\mathrm{Al}$ die grondmonsters is in die porosfeer van plante geneem en in die laboratorium deur middel van die Berlese-Tullgren ekstraksiemetode geëkstraheer. Sortering en identifisering is uitgevoer en ' $n$ verwysingsversameling is saamgestel en in etanol gestoor.

Fluktuasies in die diversiteit van die geselekteerde fauna is reg deur die studie waargeneem. Landboupraktyke het 'n besliste invloed op die intensiteit van hierdie fluktuasies gehad. Meganiese en chemiese versteurings het' $n$ aanvanklike afname in diversiteit getoon, gevolg deur 'n toename. Hierdie toenames was soms baie opvallend omdat sommige spesies in die afwesigheid van kompetisie en predatoriese druk floreer, veral in die geval van indringerspesies. Grond met ' $n$ hoër organiese samestelling bied meer weerstand teen versteuring. Diebrand van plantmateriaal in landerye het ' $n$ invloed op die vertikale verspreiding van grondmesofauna. Die invloed van chemikalieë word bepaal deur die volharding van die spesifieke chemikalieë, asook die kompleksiteit van die grondgemeenskap voor blootstelling. In reeds versteurde gebiede het chemikalieë 'n groter invloed getoon as in natuurlike veld, waar slegs 'n enkele bespuiting toegedien is. Die effek van slikdambesoedeling het die diversiteit aansienlik verminder en slegs 'n paar spesies was in die besoedelde gebiede teenwoordig. Hierdie spesies kon moontlik hier voorgekom het weens hul vermoë om swaarmetaalvergiftiging te vermy of te verdra.

Minimaal-ontwrigte landerye met organiese materiaal toon 'n hoër toleransie vir versteuring, en kan dus steeds ekosisteemdienste in die teenwoordigheid van beperkte noodsaaklike versteurings lewer as gevolg van 'n komplekse grondgemeenskapstruktuur.

Nota: 'n Seleksie van referaatopsommings: Studentesimposium in die Natuurwetenskappe, 31 Oktober - 1 November 2019 , Universiteit van die Vrystaat. Reëlingskomitee: Prof Rudi Pretorius (Departement Geografie, Universiteit van Suid-Afrika); Dr Hertzo Bisset (Suid-Afrikaanse Kernenergie-korporasie; Dr Ernie Langner (Departement Chemie, Universiteit van die Vrystaat) en Dr Wynand $\mathrm{Nel}$ (Departement Rekenaarwetenskap en Informatika, Universiteit van die Vrystaat). 